\title{
Analysis of $T$ cell subsets in lichen planus- a perception to pathogenesis
}

\author{
Shubha R. ${ }^{1}$, Thakur A.S. ${ }^{2}$, Manjunatha Y.A. ${ }^{3}$ \\ ${ }^{1}$ Dr. R. Shubha Sangeetha, Associate Professor, ${ }^{2}$ Dr. Anamika Singh Thakur, Postgraduate student, ${ }^{3}$ Dr. Y.A. Manjunatha, \\ Professor \& Head of Department, all the authors are affiliated with the Department of Pathology, Dr. B R Ambedkar Medical \\ College, Bangalore, Karnataka, India.
}

Corresponding Author: Dr. Anamika Singh Thakur, Postgraduate student, Department of Pathology, Dr. B R Ambedkar Medical College, Bangalore, Karnataka, India. E-mail: samsann24@gmail.com

\begin{abstract}
Introduction: Lichen planus (LP) is a chronic inflammatory dermatosis, histopathologically characterized by band like lymphohistiocytic infiltrate obscuring the dermo-epidermal interface and associated with basal cell vacuolar degeneration. Cell mediated cytotoxicity as evidenced by dermal $\mathrm{T}$ lymphocytes have been postulated to initiate or stimulate the pathogenic mechanisms for Lichenoid dermatitis. Aims and Objective: The aim of the study is 1) To determine the T cell subsets in the inflammatory population. 2) To analyze the pattern of distribution of T cells subsets in histopathologically diagnosed cases of LP. Materials and Method: Biopsies received from Dermatology department of Dr B R Ambedkar Medical College and histopathologically diagnosed as LP were subjected for immunohistochemistry for CD4 and CD8.Manual quantification and distribution of $\mathrm{T}$ cell subsets were analyzed by 2 individual observers. Result: Forty cases of LP diagnosed histopathologically were subjected for immunohistochemistry for CD4 and CD8. The mean age of the patients were 35.74 years with slight female predominance (F:M ratio 1.5:1). A mixed CD4 and CD8 phenotypes were identified in inflammatory population. At the dermoepidermal junction the mean CD8+ T cells subset was $67.5 \pm 9.92 \%$ and mean CD4+ T cells was $32.5 \pm 9.92 \%$. Perivascular quantification revealed a mean CD4+ T cells of 55 $10.82 \%$ and mean CD8+ T cells of $45 \pm 10.82 \%$. Conclusion: In LP cases as CD8+ cytotoxic T cells density was more in D-E Junction compared to CD4+ T helper cells, a pathogenetic role of CD8+ T cells can be highlighted in basement membrane damage. An increase in perivascular CD 4+ T cells concentration signifies the pathogenetic role of dual $\mathrm{T}$ cell subsets in LP. This study would perhaps give a better insight to dermatologist to improvise the treatment response.
\end{abstract}

Keywords: Lichen Planus (LP), Immunohistochemistry, T Cell Subsets, CD4+ T Cell, CD8+ T Cell, D-E Junction (DermoEpidermal junction)

\section{Introduction}

Lichen planus is a chronic or subacute, intensely pruritic, symmetrical, papulosquamous dermatosis, that may involve skin, mucous membranes, hair follicles, and nails with Oral involvement seen in $60 \%$ of the cases. Age of presentation is fourth to sixth decades of life with a slight female predominance [1]. The histological features of lichen planus are compact hyperkeratosis without parakeratosis, thickening or prominent granular layer, sawtooth acanthosis, band like lymphocytic infiltrate at the DE Junction, basal cell vacuolar degeneration and dyskeratotic keratinocytes. Parakeratosis is present in oral lichen planus $[2,3]$.

Pathogenesis of LP is poorly understood. De Panfilis et al. proposed that activated $\mathrm{T}$ cells may view keratinocytes as "target" cells and interact with them [4]. There is production

Manuscript received: $20^{\text {th }}$ October 2019

Reviewed: $30^{\text {th }}$ October 2019

Author Corrected: $5^{\text {th }}$ November 2019

Accepted for Publication: $11^{\text {th }}$ November 2019 of INFr and intercellular adhesion molecules (ICAM- 1) which facilitates the interaction between lymphocytes and keratinocytes resulting in band like infiltration of lymphocytes close to the dermo-epidermal junction [5]. When there is contact with the target cell and activation there is release of perforins and granzymes which cause DNA degradation and apoptosis of target cells [5].

\section{Material and Methods}

This prospective study was conducted in the Department of Pathology Dr B R Ambedkar Medical College and Hospital Bangalore over a period of one year from November 2017 to November 2018. The punch biopsies clinically diagnosed as Lichen Planus which was received from Department of Dermatology in our tertiary care hospital was included in the study. Details about the age, sex and site of the lesion were obtained from the clinical requisition.

Pathology Update: Tropical Journal of Pathology \& Microbiology Available online at: www.medresearch.in 892 | P a g e 
Duration and type of study: 1 year from November 2017 to November 2018. A Prospective Study in tertiary care hospital.

Sampling: Systemic Random sampling. The sample size was calculated by Danial's sample size estimation formulae.

Inclusion criteria: All histopathologically proven cases of Lichen Planus were included in the present study

Exclusion criteria: Patients on treatment and other lesions of interface dermatitis.

Data collection and analysis: All cases histopathologically proven as lichen planus were included in the present study and Statistical software namely SPSS 22.0, and R environment ver.3.2.2 were used for the analysis of the data and Microsoft word and Excel have been used to generate graphs, tables etc.

Ethical clearance was obtained from Institutional research board.

\section{Preparation of specimen \& diagnostic approach}

All these skin biopsies were fixed in 10\% formalin and subsequently embedded in paraffin. The 3 to 5 -micron thin sections were stained with haematoxylin and eosin. A total of 40 cases were observed under light microscopy to note the epidermal and dermal changes and diagnosis of lichen planus was considered and subjected to immunohistochemistry for T Cell subset analysis.

Immunohistochemistry was performed on formalin fixed, paraffin embedded sections as described earlier for T helper cell subset (CD4, Biocare Medicals USA) and T cytotoxic /suppressor subsets (CD8, Biocare Medicals USA) by using immunoperoxidase technique.

The biopsies were examined for $\mathrm{T}$ cell distribution at two different locations - Dermo- epidermal Junction and the perivascular region.

The quantification of $\mathrm{T}$ cell subsets $\mathrm{CD} 4+$ and $\mathrm{CD} 8+$ was done by two individual reporting histopathologists at $40 \mathrm{x}$ magnification for 10 consecutive fields at the above said location.

A mean value of the observations was taken and percentage of CD4+ and CD8+ T Cell subset was calculated at both the locations. The significant difference between the $\mathrm{T}$ cell population at different locations was analysed and the CD4:CD8 ratio was determined.

\section{Result}

Out of total 40 cases diagnosed as Lichen Planus the mean age distribution in the present study was 35.75 years with a range of 10 to 80 years as depicted in (Figure 1). The maximum number of cases were seen in 31 to 40 years of age.

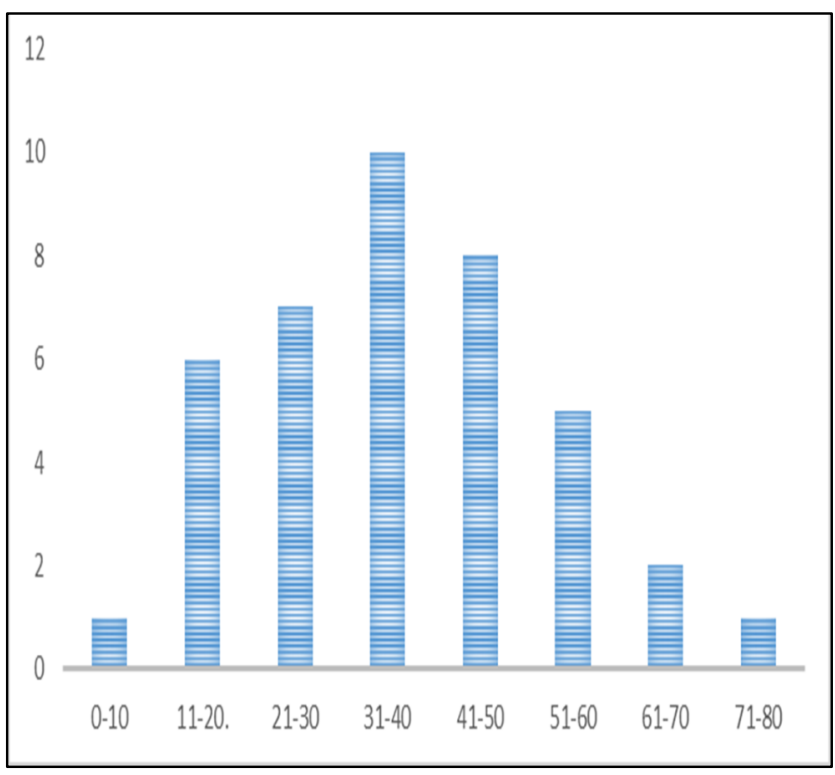

Fig-1: Age distribution.

In the present study the most common site of lesion was arms followed by legs, ankles, lumber area and head and neck and the least being the perineal region. Out of the 40 cases 24 cases $(60 \%)$ were seen in females where as 16 cases (40\%) in males (Figure 2) with male is to female ratio of 1:1.5. 


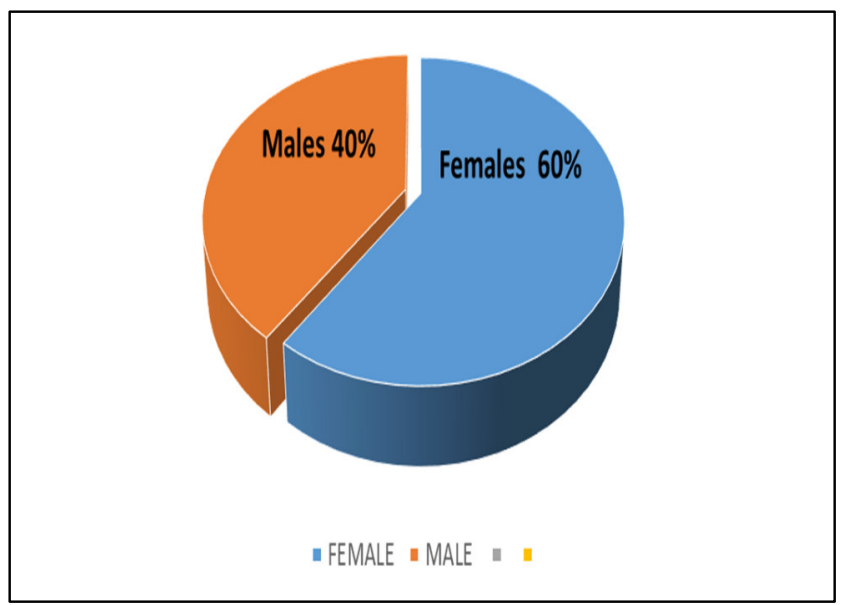

Fig-2: Sex distribution.

The CD4:CD8 ratio in the normal skin was 00- 0.30 (Figure 3). The relative percentage of CD4 and CD8 T Cells at the dermoepidermal junction and perivascular region is as tabulated in Table 1.

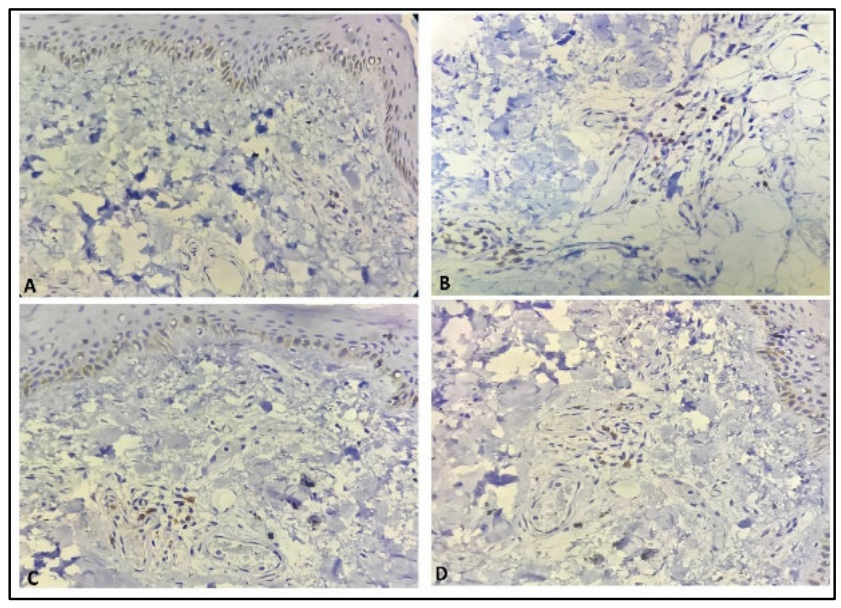

Fig-3: Immunohistochemistry of CD4+T cell in the normal skin in the D- E Junction and Perivascular region (A and B) and CD8+ $\mathrm{T}$ Cell in the normal skin in the D-E Junction and perivascular region. (C\& D at 10x magnification).

Table-1: Mean of $T$ Cells in the given Location in cases of LP.

\begin{tabular}{|c|c|c|c|}
\hline SITE & $\begin{array}{c}\text { CD4 T Cell count } \\
(\text { Mean } \pm \text { SD) }\end{array}$ & $\begin{array}{c}\text { CD8 T Cell count } \\
(\text { Mean } \pm \text { SD) }\end{array}$ & CD4:CD8 ratio \\
\hline Demo- epidermal junction & $32.5 \pm 9.92 \%$ & $67.5 \pm 9.92 \%$ & $0.42-0.48$ \\
\hline Perivascular Region & $55 \pm 10.82 \%$ & $45 \pm 10.82 \%$ & $0.79-1.34$ \\
\hline
\end{tabular}

In cases of $\mathrm{LP}$ the mean CD8+ $\mathrm{T}$ cells subset was $67.5 \pm 9.92 \%$ in the dermo-epidermal junction and mean CD4+ $\mathrm{T}$ cells was $32.5 \pm 9.92 \%$ indicating that CD8 $+\mathrm{T}$ Cells were more concentrated in this region Perivascular quantification revealed a mean $\mathrm{CD} 4+\mathrm{T}$ cells of $55 \pm 10.82 \%$ and mean $\mathrm{CD} 8+\mathrm{T}$ cells of $45 \pm 10.82 \%$ which signifies that $\mathrm{CD} 4+\mathrm{T}$ Cells were more quantified in perivascular region.

The CD4:CD8 ratio in the D- E Junction was in a range of $0.42-0.48$. and the CD4:CD8 ratio in the perivascular region was $0.79-1.34$.

\section{Discussion}

This study was undertaken to emphasize the possible role of $\mathrm{T}$ cell subsets in the pathogenesis of lichenplanus by analyzing the distribution and quantification of $\mathrm{T}$ Cell subsets. 
Histopathologically Lichen Planus is characterized by compact orthokeratosis in the cornified layer with absence of parakeratosis, wedge-shaped hypergranulosis with increase in size of granular cell layer and contain coarse and more abundant keratohyaline granules, irregular saw-toothed acanthosis and vacuolar alteration of the basal layer and a bandlike dermal lymphocytic infiltrate. The basal layer keratinocytes are not clearly visible in early lesions because the dense dermal infiltrate obscures the dermal- epidermal junction with vacuolar alteration and necrosis of these cells. Also seen are civatte bodies [6] (Figure 4).

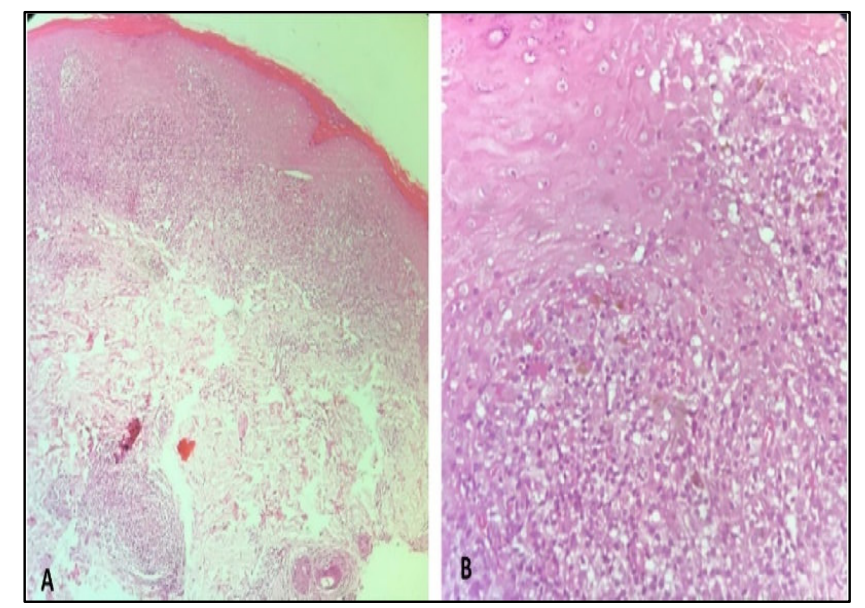

Fig-4: A. A band like lymphohistiocytic infiltrate obscuring the dermo- epidermal junction. (10x H \& E). B. Basal cell vacuolar degeneration with civette bodies, lymphocytic infiltrate and melanin incontinence (40x H \& E).

Cell-mediated cytotoxicity is regarded as a major mechanism of pathogenesis of lichen planus, as evidenced by $\mathrm{T}$ cells being the predominant cells in the inflammatory infiltrate [7]. Various factors may precipitate the cell mediated reaction resulting in lichen planus lesions. These factors include mechanical trauma, contact sensitivity systemic drugs, infective agents which include some viruses. The cytoplasm of cytotoxic cells is enriched with granules composed of the potent cytolytic molecule perforin (pore forming protein) together with serine esterase (granzymes) [5].

When there is contact with the target cell and activation there is release of perforins and granzymes which cause DNA degradation and apoptosis of target cells. Normal epidermis is resistant to interaction with leukocytes because its keratinocytes have low constitutive expression of ICAM-1 [5]. There is activation of CD8+ lymphocytes which undergo clonal expansion leading to Cross linking of Fas ligand on cytotoxic T lymphocytes, release of matrix metalloproteinase which alters extracellular matrix proteins and the release of cytotoxic molecules as granzyme B and perforin.

All these cause basement membrane disruption, subepithelial cleft formation, target cell apoptosis and lysis [6]. According to a study done by Shimizu et althere was a significant role of granzyme B-expressing CD8+ T cells in apoptosis of keratinocytes in lichen planus [8].

In the present study the cases were seen in the age group of 9 to 80 years with female preponderance and M:F ratio of 1:1.5 which is consistent with other studies like K P Kyriakis et.al [9] who had a age distribution from 5 to 83 years and M:F ratio of 1:1.4. It also correlated with study done by Parihar A et al [10] who had an age distribution of 20 to 40 years with M:F ratio $0.8: 1$.

In the current study the CD4: CD8 ratio in the normal skin in the papillary dermis was $00-0.20$ whereas the CD4:CD8 $\mathrm{T}$ cell ratio in the perivascular region was $00-0.50$ which was in concordance to the study done by Jan D Bos et al [11] (Table 2 ).

Table-2: Comparison of CD4:CD8 T Cell ratio in the normal skin.

\begin{tabular}{|c|c|c|}
\hline Study & $\begin{array}{c}\text { CD4:CD8 T Cell ratio in the papillary } \\
\text { dermis of normal skin }\end{array}$ & $\begin{array}{c}\text { CD4:CD8 T Cell ratio in the } \\
\text { perivascular region of normal Skin. }\end{array}$ \\
\hline Jan D Bos et al [11] & $0.0-0.50$ & $0.00-1.7$ \\
\hline Present Study & $0.0-0.20$ & $0.0-0.50$ \\
\hline
\end{tabular}

Pathology Update: Tropical Journal of Pathology \& Microbiology Available online at: www.medresearch.in 895 | P a g e 
In the present study the CD4+ T Cell count in Lichen Planuswas $32.5 \pm 9.92 \%$ in the dermo- epidermal junction and $55 \pm 10.82 \%$ in the perivascular region indicating an increased quantification in the perivascular region. The findings of the present study were consistent with the study done by Rana S et al [12]. The CD8 T cell count in Lichen Planus in the present study was $67.5 \pm 9.92 \%$ in the dermo- epidermal junction which was significantly higher than $32.5 \pm 9.92 \%$ in the perivascular region (Figure 5, Figure 6). These findings were in concordance with the study done by Rana $\mathrm{S}$ et al [12]. As not many studies are done to determine the CD4 and CD8 cell count in the cutaneous lichen planus not much data was available for comparison.

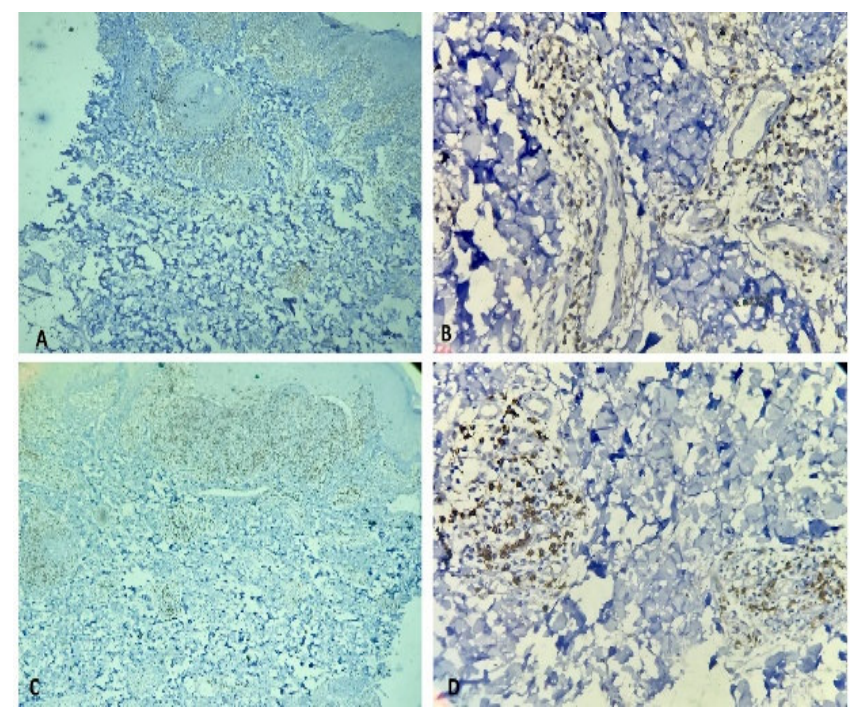

Fig-5: Immunohistochemistry. A \& B.CD4+ T cell in Lichen planus at the Perivascular region (10x and 40x). C \& D CD8+ T Cell in Lichen Planus at the Perivascualr region (10x and 40x).

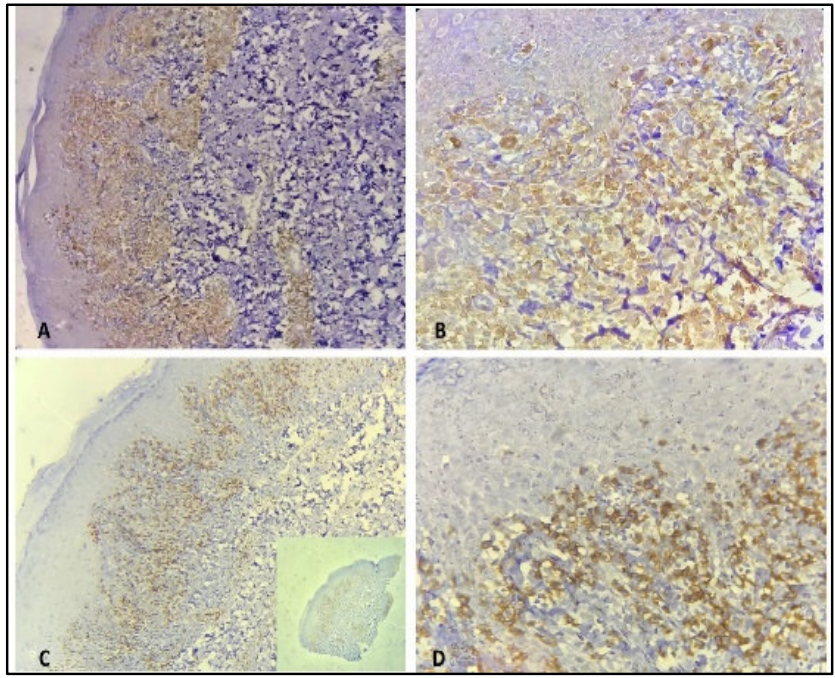

Fig-6: Immunohistochemistry. A \& B.CD4+ T cell in Lichen planus at the D- E Junction (10x and 40x). C \& D CD8+ T Cell in Lichen Planus at the D-E Junction. (10x and 40x). Inset scanner view.

In the present study CD4:CD8 ratio in the D- E Junction of cases of LP was in a range of 0.42-0.48 which was in concordance with the study done by Rana $\mathrm{S}$ et al [12]. It was also correlating with the study done by Tirumalae $\mathrm{R}$ et al [13] who described the CD4:CD8 ratio of 0.9 in inflammatory disease. The CD4:CD8 ratio in the dermo-epidermal junction was also in comparison with Scott R. Florell et al [14] who described a ratio of 1 in benign conditions (Table 3).

The CD4:CD8 ratio in the perivascular region of the cases of LP was in a range of 0.79-1.34 which was correlating with the study done by Rana $\mathrm{S}$ et al [12].

Limitations- Though not significant minimal subjective variation in immunohistochemistry interpretation was encountered. 
Table-3: Comparison of CD4:CD8 Tcell ratio in different studies.

\begin{tabular}{|c|c|c|}
\hline Study & $\begin{array}{c}\text { CD4:CD8 T Cell Ratio in D- } \\
\text { E Junction in LP cases }\end{array}$ & $\begin{array}{c}\text { CD4:CD8 T Cell Ratio in } \\
\text { Perivascular region in LP cases. }\end{array}$ \\
\hline Rana S et al [12] & 0.47 & 2.29 \\
\hline $\begin{array}{c}\text { Tirumalae R et al [13] } \\
\text { (in the inflammatory diseases) }\end{array}$ & 0.9 & -- \\
\hline R. Florell et al (for benign conditions) [14] & 1 & -- \\
\hline Present study & $0.42-0.48$ & $0.79-1.22$ \\
\hline
\end{tabular}

\section{Conclusion}

The present results have demonstrated quantitative differences in the distribution of lymphocyte subsets in the dermo- epidermal junction and perivascular region. Cutaneous Lichen Planus is a T cell mediated inflammatory dermatosis with density of CD8 T Cells increased at the DE Junction compared to CD4+ $\mathrm{T}$ helper cells which highlights the pathogenetic role of $\mathrm{CD} 8+\mathrm{T}$ cell in basement membrane damage where as an increase in perivascular $\mathrm{CD} 4+\mathrm{T}$ cells concentration signifies the role of dual T cell subsets in the pathogenesis of Lichen Planus.

\section{What the study adds to the existing knowledge?}

This study would perhaps give a better insight on pathogenesis of Lichen Planus thereby helping the dermatologist to improvise the treatment response.

\section{Author's contributions}

The work was carried out as a collaboration from all the authors. Analysis and interpretation specially involving IHC of CD4 T Cells and CD8 T cell counting at D-E junction and perivascular region was done by Dr. R. Shubha Sangeetha and Dr. Anamika Singh Thakur.

Data collection and compilation was done by the Dr. Anamika Singh Thakur \& Dr. Y.A. Manjunatha.

The final manuscript was approved and overviewed by all the authors.

Funding: No funding sources

Conflict of interest: None declared

Ethical Approval: This study was approved by the Institutional Ethics Committee

\section{References}

1. McKee P, Calonje E, Brenn T, Lazar A. McKee's pathology of the skin. Edinburgh: Elsevier Saunders; 2012.

2. Feldman SR, Sangueza OP, Pichardo-Geisinger R, Kinney M, Feneran A, Narahari S. Dermatopathology Primer of Inflammatory Diseases. CRC Press; 2013 Dec 3.
3. Billings S, Cotton J. Inflammatory Dermatopathology A Pathologist's Survival Guide $2^{\text {nd }}$ ed. Switzerland: Cleveland Springer; 2016.

4. De Panfilis G, Manara G, Sansoni P, Allegra F. T-cell infiltrate in lichen planus. Demonstration of activated lymphocytes using monoclonal antibodies. J Cutan Pathol. 1983; 10(1): 52-58. doi:10.1111/j.1600-0560. 1983. tb 00315.x.

5. Sehgal VN, Srivastava G, Sharma S, Sehgal S, Verma P. Lichenoid tissue reaction/interface dermatitis: recognition, classification, etiology, and clinicopathological overtones. Indian J Dermatol Venereol Leprol. 2011;77(4):418-429; quiz 430. doi: 10.4103/0378-6323.82389.

6. Mobini N, Toussaint S, Kamino H. Histopathology of Skin, 10th ed Philadelphia: Wolters Kluwer Health / Lippincott Williams \& Wilkins Publication; 2009.

7. Iijima W, Ohtani H, Nakayama T, Sugawara Y, Sato E, Nagura $\mathrm{H}$, et al. Infiltrating CD8+ $\mathrm{T}$ cells in oral lichen planus predominantly express CCR5 and CXCR3 and carry respective chemokine ligands RANTES/CCL5 and IP10/CXCL10 in their cytolytic granules: a potential selfrecruiting mechanism. Am J Pathol. 2003;163(1):261-268. doi: 10.1016/S0002-9440(10)63649-8.

8. Shimizu M, Higaki Y, Higaki M, Kawashima M. The role of granzyme B-expressing CD8-positive $\mathrm{T}$ cells in apoptosis of keratinocytes in lichen planus. Arch Dermatol Res. 1997; 289 (9): 527-532. doi: 10.1007/ s004030050 234.

9. Kyriakis KP, Terzoudi S, Palamaras I, Michailides C, Emmanuelidis S, Pagana G. Sex and age distribution of patients with lichen planus. J Eur Acad Dermatol Venereol. 2006; 20 (5): 625-626. doi: 10.1111/j. 1468-3083. 2006. 01513.x

10. Parihar A, Sharma S, Bhattacharya S, Singh U. A clinicopathological study of cutaneous lichen planus. J Dermatol \& Dermatol Surg. 2015;19(1):21-26. doi: https:// doi.org/10.1016/j.jssdds.2013.12.003. 
11. Bos JD, Zonneveld I, Das PK, Krieg SR, van der Loos CM, Kapsenberg ML. The skin immune system (SIS): distribution and immunophenotype of lymphocyte subpopulations in normal human skin. J Invest Dermatol. 1987;88(5):569-573. doi: 10.1111/1523-1747.ep12470172.

12. Rana S, Gupta R, Singh S, Mohanty S, Gupta K, Kudesia M. Localization of T-cell subsets in cutaneous lichen planus: An insight into pathogenetic mechanism. Indian J Dermatol Venereol Leprol. 2010;76(6):707-709. doi : 10.4103/0378-6323.72452.
13. Tirumalae R, Panjwani PK. Origin Use of CD4, CD8, and CD1a Immunostains in Distinguishing Mycosis Fungoides from its Inflammatory Mimics: A Pilot Study. Indian J Dermatol. 2012;57(6):424-427. doi: 10.4103/00195154. 103060.

14. Florell SR, Cessna M, Lundell RB, Boucher KM, Bowen GM, Harris RM, et al. Usefulness (or lack thereof) of immunophenotyping in atypical cutaneous T-cell infiltrates. Am J Clin Pathol. 2006;125(5):727-736. doi: 10. 1309/3JK2-H6Y9-88NU-AY37.

\section{How to cite this article?}

Shubha R, Thakur A.S., Manjunatha Y.A. Analysis of T cell subsets in lichen planus- a perception to pathogenesis. Trop J Path Micro 2019;5(11):892-898.doi:10.17511/jopm.2019.i11.10 